\title{
Mid-term Results of an Anterior Plating Via Combined Anterior Approach for complex Acetabular Fractures: A Retrospective Cohort Study
}

\section{Weikun Meng}

Kunming Medical College Fourth Affiliated Hospital

\section{Yi Ou}

Kunming Medical College Fourth Affiliated Hospital

\section{Zhaoxiang Wu}

Kunming Medical College Fourth Affiliated Hospital

\section{Hongchang Yang}

Kunming Medical College Fourth Affiliated Hospital

\section{Ge Chen}

Kunming Medical College Fourth Affiliated Hospital

\section{Xin Bi}

Kunming Medical College Fourth Affiliated Hospital

Liang Gao ( $\sim$ lianggao22@gmail.com )

Saarland University Medical Center https://orcid.org/0000-0003-1438-9670

\section{Zhong Chen}

Kunming Medical College Fourth Affiliated Hospital

\section{Research article}

Keywords: Complex acetabular fracture, Anterior plating, Ilioischial plate, Modified Stoppa approach, Three-Column classification

Posted Date: August 12th, 2020

DOI: https://doi.org/10.21203/rs.3.rs-51697/v1

License: (c) (i) This work is licensed under a Creative Commons Attribution 4.0 International License. Read Full License 


\section{Abstract}

Background: Solely anterior plating via the modified Stoppa approach might yield satisfactory outcomes for selected cases of complex acetabular fractures, however, its indications are not practically clear.

Methods: Patients with complex acetabular fractures treated with solely anterior plating via the modified Stoppa approach with or without a lateral window at our trauma center between January 2013 and December 2019 were retrospectively reviewed. Fracture type was identified according the newly established three-column classification of acetabular fracture. Perioperative information was recorded, and fracture reduction was evaluated radiographically at 3 days postoperatively. Postoperative hip function was assessed at least 1 year postoperatively.

Results: Twenty patients were included with an average 17 months (range, 13-28) follow-up. According to the three-column classification, 2 cases were classified as type B2.2, 8 cases as type B2.3, 3 cases as type $\mathrm{C} 1$, and 7 cases as type C3. The mean time from injury and surgery was 7.0 days (range, 3-13 days), operative time was 2.0 hours (range, 1.4-3.2 hours), and intraoperative blood loss was $320 \mathrm{ml}$ (range, 220$450 \mathrm{ml}$ ). Fracture reduction was excellent in 15 cases (75\%), good in 3 cases (15\%), fair in 1 case (5\%), and poor in 1 case (5\%). Final hip function was excellent in 13 cases (68\%), good in 3 cases (16\%), fair in 2 cases $(11 \%)$, and poor in 1 case (5\%). Bony healing was achieved in all cases and few complications were reported including recoverable obturator nerve injuries in 2 patients $(10 \%)$ and controllable osteoarthritis in 1 patient (5\%).

Conclusions: Solely anterior plating via the combined anterior approach achieved satisfactory mid-term outcomes for complex acetabular fractures with posterior column detachments. Based on the newly established three-column classification of complex acetabular fracture, the type B, C1, and C3 fractures are possibly the appropriate indications for such a simplified procedure.

\section{Trial registration information}

The trial was retrospectively registered in https://www.researchregistry.com (No. Researchregistry4862) on July 04, 2019. The first participant was enrolled on March 06, 2017.

\section{Background}

The advantages of simultaneous anterior and posterior approaches over extensile exposures allowing adequate visualization and/or palpation of the fracture to obtain an anatomic reduction [1]. The combined approach is most useful in transverse, transverse posterior wall fractures with wide anterior displacement, $T$ type fractures with significant anterior-inferior displacement, or both column fractures with posterior wall involvement [1]. Controversies still exist regarding the optimal surgical approach for achieving better exposure of fracture sites, less soft tissue damage and lower complications rates in 
complex acetabular fractures [2-7]. Simultaneous anterior (e.g. ilioinguinal approach, pararectus approach, and modified Stoppa approach) and posterior approaches (e.g. Kocher-Langenbeck approach) are usually applied [8-10], however, they occasionally show noteworthy drawbacks (e.g. long operating time and substantial blood loss) and complications (e.g. structure damage, infection, abductor weakness, and hernia) compared with other mini-invasive approaches [11-13]. As a less invasive approach, the anterior modified Stoppa approach with or without the lateral window of the classic ilioinguinal approach allows for easier accessing the entire anterior column and pelvic bone $[8,14]$ and for additional exposure of the quadrilateral surface and posterior column $[15,16]$. Adequate reduction of the posterior column can be attained through such a combined anterior approach. Practically, an ilioischial plate bridging from ilium to ischial ramus to fix the quadrilateral plate or lag screws to fix the detached posterior column can be used. Our previous case series showed that anterior ilioischial plating in 7 patients via the modified Stoppa approach provides reliable internal fixation of complex acetabular fractures with posterior column detachments with limited invasion, little intraoperative bleeding and few complications at 6 months postoperatively [17].

Based on the widely-used Judet and Letournel classification [18], indications of such a simplified anterior approach include the elementary and associated displaced acetabular fractures involving predominantly the anterior, incongruency of the hip joint, involvement of the weight-bearing dome, impaction of the weight-bearing dome, comminution of the articular surface, unstable hip joint, associated proximal femoral injuries (femoral neck or trochanteric fractures), associated non-orthopaedic injuries (nerve deficits and/or bowel or bladder injuries) [19]. However, the Judet and Letournel classification is practically cumbersome and complex and results in various inaccuracies to guide clinical decisions [2022]. A three-column classification for acetabular fractures (Table 1 ) has been recently proposed and validated with higher inter- and intra-observer reliability than the Judet and Letournel classification [23], which might be effective to identify more proper candidates of the modified Stoppa approach for complex acetabular fractures with posterior column detachments. 
Table 1

Three-Column classification for acetabular fractures [22].

A (single column or wall detachment)

A1 (anterior column or wall)

A1.1 (anterior wall)

A1.2 (anterior column)

A1.3 (complicated anterior column)

A2 (posterior column or wall)

A2.1 (posterior wall)

A2.2 (posterior column)

A2.3 (complicated posterior column)

A3 (roof column or wall)

A3.1 (roof wall)

A3.2 (roof column)

A3.3 (complicated roof column)

A4 (medial wall)

B (2-column detachment)

B1 (roof-anterior columns)

B1.1 (intact roof-anterior columns)

B1.2 (separated roof-anterior columns)

B1.3 (complicated roof-anterior columns)

B2 (anterior-posterior columns)

B2.1 (intact anterior-posterior columns)

B2.2 (separated anterior-posterior columns)

B2.3 (complicated anterior-posterior columns)

C (3-column detachment)

C1 (elementary 3-column)

C2 (3-column with posterior wall)

C3 (complicated 3-column) 
Therefore, the present cohort study aimed to evaluate the mid-term outcomes of the anterior plating via the modified Stoppa approach to treat complex acetabular fractures with posterior column detachments and to identify its possible indications based on the newly established three-column classification.

\section{Methods}

\section{Study design}

Patients with complex acetabular fractures operated at our trauma center by the identical senior surgeon team between January 2013 and December 2019 were retrospectively reviewed with the approval of local ethics committee (No. H01170195). Inclusion criteria were patients with acute acetabular fractures with posterior column detachments operated via a single modified Stoppa approach. Patients with only anterior wall/column or roof wall/column fractures and patients accompanied with osteoporosis, osteoarthritis, or other systemic illnesses (e.g. hyperthyroidism, hyperparathyroidism, androgen deficiency, malabsorption, and neoplasia) were excluded. All patients underwent a standardized assessment including medical history, clinical examination and imaging studies. Fracture type and displacement was assessed with plain radiographs and computed tomography with 3D reconstruction. The primary endpoints were postoperative reduction (perfect reduction, imperfect reduction, poor reduction) and hip function. The secondary endpoints were infection, never damage, blood loss, and duration of operation.

\section{Surgical procedure}

All patients underwent the modified Stoppa approach as previously described [24]. Patients were placed in a supine position on a radiolucent table allowing for unrestricted movements of the lower extremities. The affected lower extremity was sterilized and wrapped to the middle of the thigh. The hip and knee of the affected extremity were flexed slightly to relax the iliopsoas and neurovascular bundle. The modified Stoppa approach with or without the 1st window of the ilioinguinal approach was performed as previously described $[25,26]$. Foley catheter and drainage system are used to improve visualization, protect bladder, and monitor fluid balance. A transverse Pfannenstiel-type incision of 12-15 cm was achieved two fingerbreadths above the pubic symphysis and deepened to the abdominal fascia. The inner part of the pelvis was approached by dissecting the exposed rectus abdominis along the linea alba. Specifically, the corona mortis was firstly identified and ligated, and fracture fragments were exposed via the subperiosteal dissection along the pelvic brim. Obturator nerve and vessels passing through the obturator foramen were identified and protected. A Schanz screw was inserted into the proximal femur allowing for intraoperative manual traction and fractures were reduced with assistance of different reduction instruments (e.g. ball spike and reduction forceps). Fragments were temporarily fixated with Kirschner wires and anatomic reconstruction of the different fracture fragments was confirmed. Infrapectineal or suprapectineal plates $(3.5 \mathrm{~mm}$; 8 hole) contoured along the pelvic brim was anchored with cortical screws above the sciatic notch. Another plate, termed as the "ilioischial plate", was contoured over the pelvic brim to buttress comminution or counteract posterior column medial displacement (Fig. 1). 
Displaced quadrilateral surface fragments were meticulously reduced and buttressed with the bridging effect of the ilioischial plate. Anchorage of the ilioischial plate was attained with cortical screws to the iliac fossa and the safe zone between the sciatic buttress and the ischial spine. For specific cases with comminuted fragments of the posterior column, an additional lag screw was inserted from anterior to posterior direction within the safe zone to fix those fragments to provide further stabilization of the posterior fragments. Operative data was recorded for each patient including interval between injury and surgery, operative time and intraoperative blood loss.

\section{Postoperative management}

Standardized postoperative care was provided for all patients. The operated limb was elevated slightly with both hip and knee appropriately flexed. Wound drainage was removed 24-72 hours postoperatively. Oral administration of celecoxib was applied for pain control and heterotopic ossification prevention. Low-molecular-weight heparin was used for thrombosis prevention. Rehabilitation was initiated after 24 hours postoperatively to improve blood circulation and prevent deep vein thrombosis and muscular atrophy. Ambulation with crutches was allowed at 3 days postoperatively. Patients are generally discharged at 5 days postoperatively, when they present no complications. Partial weight-bearing exercises and ambulation without crutches were started at the postoperative 6 and 12 weeks, respectively.

\section{Outcome evaluation}

Quality of the fracture reduction was evaluated with the modified Matta's criteria on the plain radiographs at 3 days postoperatively [27]. Reduction was classified as: excellent (anatomical reduction), good (0$1 \mathrm{~mm}$ residual displacement), fair (2-3 $\mathrm{mm}$ residual displacement), and poor ( $>3 \mathrm{~mm}$ residual displacement). Function of the affected hip was evaluated using the modified Merle d'Aubigné and Postel scoring system over 1 year postoperatively [28]. Hip function was considered to be: excellent (no pain, a normal gait, a range of joint motion $>75 \%$, no sign of arthritic changes or mild joint space narrowing or

sclerosis on X-ray), good (mild pain, a normal gait, a range of joint motion $>50 \%$, joint surface sclerosis or joint space narrowing or osteophyte formation), fair (moderate pain, mild abnormality of gait, a range of joint motion $<50 \%$, significant joint space narrowing or joint surface sclerosis and osteophyte formation), and poor (severe pain, obvious gait abnormality, joint stiffness with deformity, significant arthritic changes or obvious dislocation of the femoral head).

\section{Statistical analysis}

Descriptive statistics are used to describe the results. Data are presented as the mean \pm standard deviation, range, and percentage, where appropriate.

\section{Results}

\section{Demographic characteristics}


A total of 20 patients were enrolled in this study, including 12 males $(60 \%)$ and 8 females $(40 \%)$ at the mean age of 45 years old (range, 16-62). Nine cases (45\%) were left-sided fractures and 11 cases (55\%) were right-sided. According to the three-column classification, 2 cases $(10 \%)$ were classified as separated anterior-posterior column fractures (type B2.2); 8 cases (40\%) as complicated anterior-posterior columns fracture without posterior wall or roof fractures (type B2.3), 3 cases (15\%) as elementary 3-column (type C1), and 7 cases (type 35\%) as complicated 3-column fracture without posterior wall or roof fractures (type C3). The postoperative follow-up was over 12 months (mean 17, range, 13-28 months), and only 1 patient was lost after 3 months' follow-up (Table 2).

Table 2

Demographic and surgery characteristics.

\begin{tabular}{|c|c|c|}
\hline \\
\hline Variables & $\begin{array}{l}\text { Patients } \\
(n=20)\end{array}$ & Range/ Percentage (\%) \\
\hline Age (years) & 45 & $16-62$ \\
\hline \multicolumn{3}{|l|}{ Gender } \\
\hline Female & 8 & 60 \\
\hline Male & 12 & 40 \\
\hline \multicolumn{3}{|l|}{ Side of injury } \\
\hline Right & 11 & 55 \\
\hline Left & 9 & 45 \\
\hline \multicolumn{3}{|l|}{ Three-column classification } \\
\hline B2.2 & 2 & 10 \\
\hline B2.3 & 8 & 40 \\
\hline $\mathrm{C} 1$ & 3 & 15 \\
\hline C3 & 7 & 35 \\
\hline Time from injury to surgery (days) & 7.0 & $3-13$ \\
\hline Operation time (hours) & 2.0 & $1.4-3.2$ \\
\hline Intraoperative blood loss (ml) & 320 & $220-450$ \\
\hline
\end{tabular}

\section{Operative characteristics}

The mean time to surgery was 7.0 days (range, 3-13 days). Operative time was 2.0 hours (range, 1.4-3.2 hours). Intraoperative blood loss was $320 \mathrm{~mL}$ (range, $220-450 \mathrm{~mL}$ ). All patients were stable without complications related to operation or anesthesiology and received no blood transfusion.

\section{Radiographic outcomes}


Based on Matta's criteria, postoperative radiographic outcome was excellent in 15 cases (75\%) (Fig. 2, Fig. 3), good in 3 cases (15\%), fair in 1 case (5\%) and poor in 1 case (5\%) (Table 3 ). Bone healing was achieved in all cases and evidenced in plain radiographs at 3 months postoperatively.

Table 3

Assessments of postoperative radiographic and clinical outcomes.

\begin{tabular}{|lll|}
\hline Outcome evaluations & Results & Percentage (\%) \\
\hline Modified Matta's criteria ${ }^{a}$ & & \\
\hline Excellent & 15 & 75 \\
\hline Good & 3 & 15 \\
\hline Fair & 1 & 5 \\
\hline Poor & 1 & 5 \\
\hline Modified Merle d'Aubigné and Postel scoring system ${ }^{\text {b }}$ & & \\
\hline Excellent & 13 & 68 \\
\hline Good & 3 & 16 \\
\hline Fair & 2 & 11 \\
\hline Poor & 1 & 5 \\
\hline${ }^{a}$ Evaluation at 3 days postop. ${ }^{b}$ Evaluation at over 1 year postop with one patient lost to follow-up. \\
\hline UnCtional OUtCOMeS
\end{tabular}

According to the modified Merle d'Aubigné and Postel scoring system, the function of the affected hip joint was excellent in 13 cases (68\%), good in 3 cases (16\%), fair in 2 cases (11\%), and poor in 1 case (5\%) (Table 3). Two patients (10\%) exhibited clinical evidences of obturator nerve injury, which were recovered fully after 3 months without special medical interventions. One patient (5\%) developed a symptomatic osteoarthritis at 2 years postoperatively, which was well diminished by medications. No other specific complications were reported in other patients, including internal fixation failure, postoperative infection, and heterotopic ossification.

\section{Discussion}

This study showed that the solely anterior plating via modified Stoppa approach achieved clinically satisfactory mid-term outcomes for complex acetabular fractures with posterior column detachments. Preoperative fracture type identification based on the novel three-column classification is facilitative to identify the appropriate candidates for such a simplified approach. 
The modified Stoppa approach with the lateral window of the classic ilioinguinal approach is practically convenient to access fracture fragments of posterior column effectively with advantages of less blood loss, shorter operation time, and fewer complications than other traditional approaches. The average intraoperative blood loss in our cohorts was $320 \mathrm{~mL}$, which was significantly less than blood loss with a single ilioinguinal approach ranging from $760 \mathrm{~mL}$ to $1170[26,29]$ or simultaneous anterior (Stoppa/iliac window approach) and Kocher-Langenbeck approach ranging from $586 \mathrm{ml}$ to $1252 \mathrm{ml}$ [30-32]. Similarly, the average operative time in our cohorts ( 2.1 hours) is considerably shorter than the single ilioinguinal approach (2.6-4.3 hours) [26, 33] and the simultaneous anterior modified ilioinguinal/Stoppa approach (2.1-4.4 hours) [30,31, 34-36]. Moreover, no heterotopic ossification and only two obturator nerve injury (recovered within 3 months postop) was observed in our cohorts, which are also significantly less than the rates of heterotopic ossification (25.6\%), traumatic nerve palsy (16.4\%), and iatrogenic nerve palsy (8.0\%) in 3670 patients reported by a recent meta-analysis [37].

Previous biomechanical experiments demonstrated that a single locking plating of the anterior column provided less stability than a traditional treatment with posterior column plating and anterior column screwing [38], however, the anterior fixation with multiple spring plates, especially the ilioischial plate, practically allows for a direct buttressing of posterior column fractures and provides clinically comparable stability as a posterior plating. The additional lag screws positioned from anterior to posterior direction can fix the fragments of the posterior columns and achieve a rigid fixation $[39,40]$. Here, all patients achieved radiographic bone healing at 3 months postoperatively with good or excellent fracture abduction and fixation in $90 \%$ cases, which are in good agreement with a previous study reporting congruent reduction in $89 \%$ cases treated with either single (anterior or posterior) approach or simultaneous anterior-posterior approach [41]. Similarly, $85 \%$ of our cases achieved good or excellent hip function at average 17-month postoperatively, consistent with a prior investigation reporting satisfactory hip function in $85.2 \%$ cases treated via simultaneous ilioinguinal and Kocher-Langenbeck approaches over 4-year postoperatively [42].

The newly established three-column classification is practical to identify the pattern of complex acetabular fracture and provides an instrumental guide to select corresponding most favorable interventions. Based on this novel classification, the indications of such a simplified approach are proposed as follows: (1) type B1.1, intact roof-anterior column fractures; (2) type B1.2, separated roofanterior column fractures; (3) type B1.3, complicated roof-anterior column fractures; (4) type B2.1, intact anterior-posterior column fractures; (5) type B2.2, separated anterior-posterior column fractures; (6) type B2.3, complicated anterior-posterior column fractures without posterior wall fractures; (7) type C1, elementary 3-column fractures; (8) and type $\mathrm{C} 3$, complicated 3-column fractures. Preoperative evaluation of patient status, fracture type, extent of the displacement, the surgeon's experience is crucial [34]. For patients with obesity or history of previous low abdominal surgeries with possible local adhesions, other approaches might be favorable. Moreover, imprudent manipulation with limited exposure might cause extensive soft tissue damages and hinder the satisfactorily reduction of fractures, possibly influencing the long-term prognosis $[11,43,44]$. Therefore, surgeons are recommended to start using this modified 
Stoppa approach after mastering the ilioinguinal approach to avoid possible iatrogenic injuries of the perifracture structures.

Several limitations exist in this study. The sample size of our cohorts was relatively small, and the followup is also relatively short, which might not allow to draw firm conclusions about ultimate efficacy of the anterior plating for complex acetabular fracture with posterior column detachments. Secondly, the retrospective analysis cannot allow for a detailed investigation of characteristics of our cohorts and a comparison with a possible control group. Moreover, long-term comparisons with traditional treatments are required to confirm the possible benefits of this procedure. Strengths of this investigation include the establishment of the indications of such a simplified approach based on the novel three-column classification and the representation of its corresponding mid-term outcomes.

\section{Conclusions}

The solely anterior plating via modified Stoppa approach achieved satisfactory mid-term outcomes for complex acetabular fractures with posterior column detachments. Based on the newly established threecolumn classification of complex acetabular fracture, the type $\mathrm{B}, \mathrm{C} 1$, and $\mathrm{C} 3$ fractures might be the appropriate indications for such a simplified procedure.

\section{Abbreviations}

3D: Three-dimensional;

CT: Computed Tomography.

\section{Declarations}

\section{Acknowledgements}

Not applicable.

\section{Funding}

The authors received no specific individual funding for this work.

\section{Availability of data and materials}

The data supporting your findings can be found and have be presented within the manuscript.

\section{Authors' contributions}


ZC conceived and designed the study. WKM, YO, ZXW, GC, XB, HCY, and LG performed the data analysis. WKM, YO and LG drafted the initial manuscript with all authors contributing substantially to the final manuscript. All authors read and approved the final manuscript.

\section{Ethics approval and consent to participate}

Ethics approval and consent to participate: This project had IRB approval from the Second People's Hospital of Yunnan Province, Kunming/Yunnan, P. R. China.

\section{Consent for publication}

Not applicable.

\section{Competing interests}

The authors declare that they have no competing interests.

\section{References}

1. Harris AM, Althausen P, Kellam JF, Bosse MJ. Simultaneous anterior and posterior approaches for complex acetabular fractures. J Orthop Trauma. 2008;22(7):494-7.

2. Tile $M$, Helfet $D L$, Vrahas $M$, Kellam JF: Fractures of the pelvis and acetabulum: principles and methods of management: Thieme; 2015.

3. Sagi HC, Jordan CJ, Barei DP, Serrano-Riera R, Steverson B. Indomethacin prophylaxis for heterotopic ossification after acetabular fracture surgery increases the risk for nonunion of the posterior wall. $J$ Orthop Trauma. 2014;28(7):377-83.

4. Rickman M, Young J, Trompeter A, Pearce R, Hamilton M. Managing acetabular fractures in the elderly with fixation and primary arthroplasty: aiming for early weightbearing. Clin Orthop Relat Res. 2014;472(11):3375-82.

5. Kuper MA, Konrads C, Trulson A, Bahrs C, Stockle U, Stuby FM: Complications of surgical approaches for osteosynthetic treatment of acetabular fractures: Analysis of pitfalls and how to avoid them. Injury 2020.

6. Gao L, Han Z, Xiong A. Total Hip Arthroplasty or Hemiarthroplasty for Hip Fracture. N Engl J Med. 2020;382(11):1072-3.

7. Meng W, Huang Z, Wang H, Wang D, Luo Z, Bai Y, Gao L, Wang G, Zhou Z. Supercapsular percutaneously-assisted total hip (SuperPath) versus posterolateral total hip arthroplasty in bilateral osteonecrosis of the femoral head: a pilot clinical trial. BMC Musculoskelet Disord. 2019;21(1):2. 
8. Stoppa RE. The treatment of complicated groin and incisional hernias. World J Surg. 1989;13(5):545-54.

9. Keel MJ, Ecker TM, Cullmann JL, Bergmann M, Bonel HM, Buchler L, Siebenrock KA, Bastian JD. The Pararectus approach for anterior intrapelvic management of acetabular fractures: an anatomical study and clinical evaluation. J Bone Joint Surg Br. 2012;94(3):405-11.

10. Tosounidis TH, Giannoudis VP, Kanakaris NK, Giannoudis PV. The Kocher-Langenbeck Approach: State of the Art. JBJS Essent Surg Tech. 2018;8(2):e18.

11. Routt ML Jr, Swiontkowski MF. Operative treatment of complex acetabular fractures. Combined anterior and posterior exposures during the same procedure. The Journal of bone joint surgery American volume. 1990;72(6):897-904.

12. Harris AM, Althausen $P$, Kellam JF, Bosse MJ. Simultaneous anterior and posterior approaches for complex acetabular fractures. J Orthop Trauma. 2008;22(7):494-7.

13. Assal M, Ray A, Fasel JHD, Stern R. A modified posteromedial approach combined with extensile anterior for the treatment of complex tibial pilon fractures (AO/OTA 43-C). J Orthop Trauma. 2014;28(6):e138-45.

14. Khoury A, Weill Y, Mosheiff R. The Stoppa approach for acetabular fracture. Oper Orthop Traumatol. 2012;24(4-5):439-48.

15. Archdeacon MT, Kazemi N, Guy P, Sagi HC. The modified Stoppa approach for acetabular fracture. JAAOS-Journal of the American Academy of Orthopaedic Surgeons. 2011;19(3):170-5.

16. Jeanny JC, Fayein N, Moenner M, Chevallier B, Barritault D, Courtois Y. Specific fixation of bovine brain and retinal acidic and basic fibroblast growth factors to mouse embryonic eye basement membranes. Exp Cell Res. 1987;171(1):63-75.

17. Yi O, Zhaoxiang W, Chen Z, Chen G, Zhao H, Xin B. Anterior fixation with oblique-ilioischial plate for acetabular fractures of lower posterior column. Chinese Journal of Orthopaedic Trauma. 2018;20(5):382-8.

18. Judet $R$, Judet $J$, Letournel E. FRACTURES OF THE ACETABULUM: CLASSIFICATION AND SURGICAL APPROACHES FOR OPEN REDUCTION. PRELIMINARY REPORT. The Journal of bone joint surgery American volume. 1964;46:1615-46.

19. Tannast M, Keel MJB, Siebenrock K-A, Bastian JD. Open Reduction and Internal Fixation of Acetabular Fractures Using the Modified Stoppa Approach. JBJS essential surgical techniques. 2019;9(1):e3-3.

20. Polesello GC, Nunes MA, Azuaga TL, de Queiroz MC, Honda EK, Ono NK. Comprehension and reproducibility of the Judet and Letournel classification. Acta Ortop Bras. 2012;20(2):70-4.

21. Beaulé PE, Dorey FJ, Matta JM. Letournel classification for acetabular fractures. Assessment of interobserver and intraobserver reliability. The Journal of bone joint surgery American volume. 2003;85(9):1704-9.

22. Petrisor BA, Bhandari M, Orr RD, Mandel S, Kwok DC, Schemitsch EH. Improving reliability in the classification of fractures of the acetabulum. Arch Orthop Trauma Surg. 2003;123(5):228-33. 
23. Zhang R, Yin Y, Li A, Wang Z, Hou Z, Zhuang Y, Fan S, Wu Z, Yi C, Lyu G, et al: Three-Column Classification for Acetabular Fractures: Introduction and Reproducibility Assessment. The Journal of bone and joint surgery American volume 2019:10.2106/JBJS.2119.00284.

24. Laflamme GY, Hebert-Davies J, Rouleau D, Benoit B, Leduc S. Internal fixation of osteopenic acetabular fractures involving the quadrilateral plate. Injury. 2011;42(10):1130-4.

25. Judet R, Judet J, Letournel E. Fractures of the Acetabulum: Classification and Surgical Approaches for Open Reduction. Preliminary Report. J Bone Joint Surg Am. 1964;46:1615-46.

26. Rocca G, Spina M, Mazzi M. Anterior Combined Endopelvic (ACE) approach for the treatment of acetabular and pelvic ring fractures: A new proposal. Injury. 2014;45(Suppl 6):9-15.

27. Matta JM. Operative treatment of acetabular fractures through the ilioinguinal approach. A 10-year perspective. Clinical orthopaedics and related research 1994(305):10-19.

28. d'Aubigné RM, Postel M. The classic: functional results of hip arthroplasty with acrylic prosthesis. 1954. Clin Orthop Relat Res. 2009;467(1):7-27.

29. Elmadağ M, Güzel Y, Acar MA, Uzer G, Arazi M. The Stoppa approach versus the ilioinguinal approach for anterior acetabular fractures: a case control study assessing blood loss complications and function outcomes. Orthop Traumatol Surg Res. 2014;100(6):675-80.

30. Sagi HC, Afsari A, Dziadosz D. The anterior intra-pelvic (modified rives-stoppa) approach for fixation of acetabular fractures. J Orthop Trauma. 2010;24(5):263-70.

31. Sharma AR, Jagga S, Lee S-S, Nam J-S. Interplay between cartilage and subchondral bone contributing to pathogenesis of osteoarthritis. Int J Mol Sci. 2013;14(10):19805-30.

32. Elmadag M, Guzel Y, Aksoy Y, Arazi M. Surgical Treatment of Displaced Acetabular Fractures Using a Modified Stoppa Approach. Orthopedics. 2016;39(2):e340-5.

33. Bi D-W, Han L, Zu G, Zheng Q, Fei J, Wei W, Gu J, Ma H-T, Chen Y-M, Hu G-F. Choice of operative approaches for complex fractures of the quadrilateral area of acetabular. Zhongguo Gu Shang. 2013;26(11):944-8.

34. Kim HY, Yang DS, Park CK, Choy WS. Modified Stoppa approach for surgical treatment of acetabular fracture. Clinics in orthopedic surgery. 2015;7(1):29-38.

35. Fan L, Jin Y-J, He L, Lü Z, Fan H-H. Modified Stoppa approach in treatment of pelvic and acetabular fractures. Zhongguo Gu Shang. 2012;25(10):810-2.

36. Wang P, Zhu X, Xu P, Zhang Y, Wang L, Liu X, Mu W. Modified ilioinguinal approach in combined surgical exposures for displaced acetabular fractures involving two columns. Springerplus. 2016;5(1):1602-2.

37. Giannoudis PV, Grotz MRW, Papakostidis C, Dinopoulos H. Operative treatment of displaced fractures of the acetabulum. A meta-analysis. J Bone Joint Surg Br. 2005;87(1):2-9.

38. Khajavi K, Lee AT, Lindsey DP, Leucht P, Bellino MJ, Giori NJ. Single column locking plate fixation is inadequate in two column acetabular fractures. A biomechanical analysis. J Orthop Surg Res. 2010;5:30-0. 
39. Mehin R, Jones B, Zhu Q, Broekhuyse H. A biomechanical study of conventional acetabular internal fracture fixation versus locking plate fixation. Can J Surg. 2009;52(3):221-8.

40. Marintschev I, Gras F, Schwarz CE, Pohlemann T, Hofmann GO, Culemann U. Biomechanical comparison of different acetabular plate systems and constructs-the role of an infra-acetabular screw placement and use of locking plates. Injury. 2012;43(4):470-4.

41. Kumar A, Shah NA, Kershaw SA, Clayson AD. Operative management of acetabular fractures. A review of 73 fractures. Injury. 2005;36(5):605-12.

42. Moroni A, Caja VL, Sabato C, Zinghi G. Surgical treatment of both-column fractures by staged combined ilioinguinal and Kocher-Langenbeck approaches. Injury. 1995;26(4):219-24.

43. Mears DC. Surgical treatment of acetabular fractures in elderly patients with osteoporotic bone. J Am Acad Orthop Surg. 1999;7(2):128-41.

44. Jeffcoat DM, Carroll EA, Huber FG, Goldman AT, Miller AN, Lorich DG, Helfet DL. Operative treatment of acetabular fractures in an older population through a limited ilioinguinal approach. J Orthop Trauma. 2012;26(5):284-9.

\section{Figures}
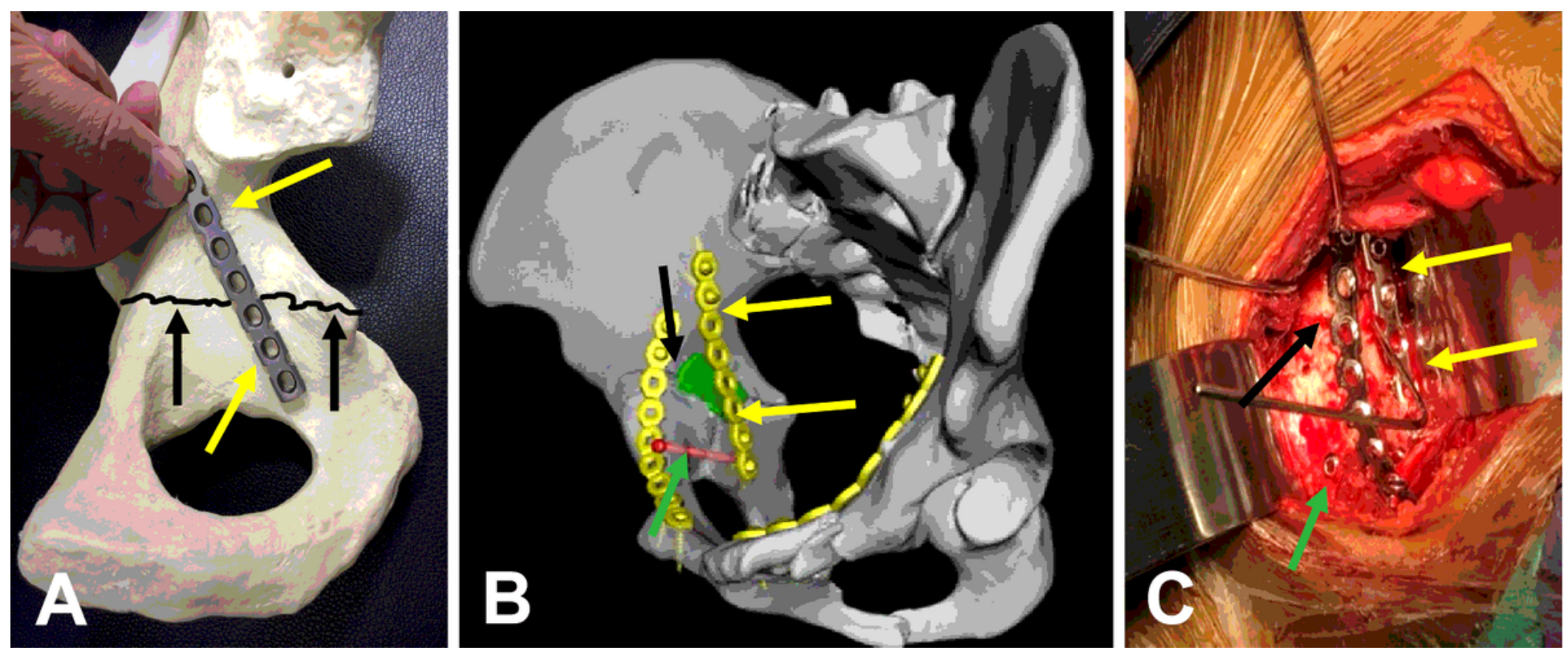

Figure 1

Illustrations of the orientation of ilioischial plate with (A) sawbone, (B) 3D reconstructed computed tomography, and $(\mathrm{C})$ intraoperative view of a patient with complicated anterior-posterior column fractures (type B2.3). The ilioischial plate should be intraoperatively contoured over the pelvic brim to counteract posterior column medial displacement. Displaced quadrilateral surface fragments were meticulously buttressed with the bridging effect. The plate was anchored with cortical screws to the iliac fossa and the safe zone between the sciatic buttress and ischial spine. An additional lag screw can be inserted from the 
anterior to posterior direction within the safe zone to provide further fixation of the posterior fragments. The black, yellow, and green arrows indicate the fracture line, ilioischial plate, and lag screw, respectively.
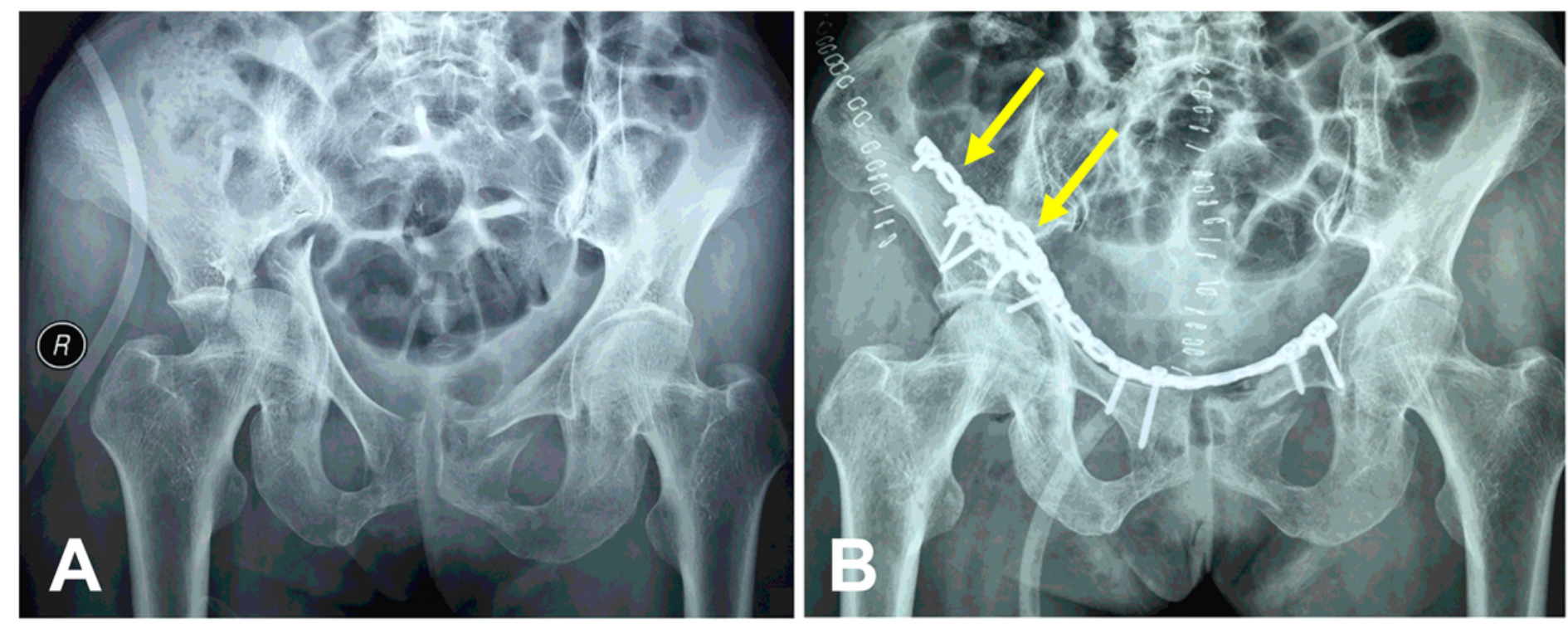

\section{Figure 2}

A 61-year-old female with a right-side separated anterior-posterior column acetabular fracture (B2.2). Anteroposterior radiographs show (A) preoperative displacement of the fracture components and (B) postoperative reduction and internal fixation with two anterior spring plates. The yellow arrows depict the ilioischial plate.
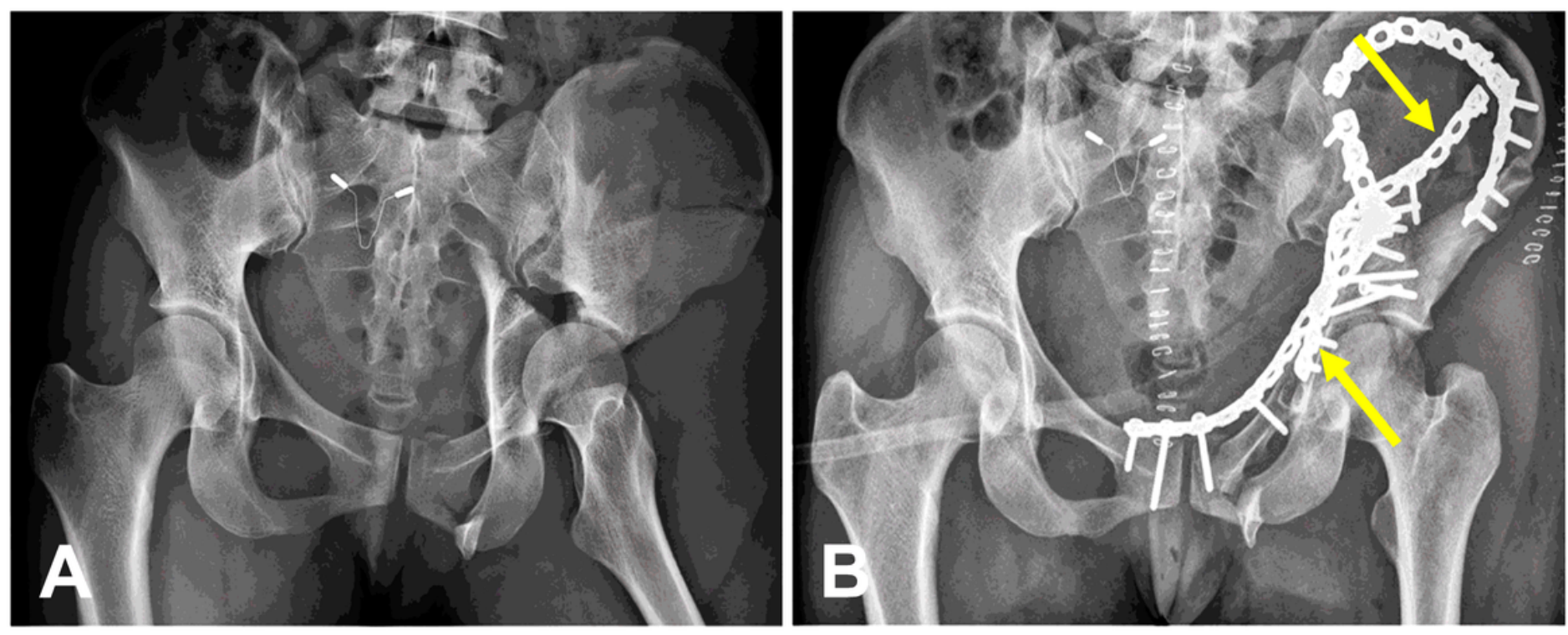

\section{Figure 3}

A 32-year-old female with a left-side complicated 3-column acetabular fracture without involving posterior wall and roof (C3). Anteroposterior radiographs show (A) preoperative displacement of the fracture 
components and (B) postoperative reduction and internal fixation with four spring plates. The yellow arrows depict the ilioischial plate. 